\title{
New Era of Teaching Learning : 3D Marker Based Augmented Reality
}

\author{
Abhijitsinh Jadeja (HOD-PGDCA , BPCCS , KSV University, Gandhinagar) \\ Richa Mehta ( Lecturer BPCCS , KSV University, Gandhinagar ) \\ Deepak Sharma( Student BPCCS , KSV University, Gandhinagar )
}

\begin{abstract}
The main objective of this paper is to provide clarity of concepts to the students in a real like environment through $3 d$ visual aids that may be used to clarify or enhance understanding of a concept or process. As a student said, "Tell me and I forget. Show me and I remember, Involve me and I understand" This paper focuses on involving the children in understanding of the concepts in $3 D$ environment. The traditional method includes concept deliverance not based on visual aids. Now the modern teaching methodology includes visual aids such as projector, transparent slides, and models in $2 d$ environment. If visual aids are converted from $2 D$ to $3 D$ environment, the student will have a live environment to understand the concepts. Visual aids tools are available to teachers to add reality, clarity, and variety to the drill which is necessary for students at the earlier stages of language learning. Augment Reality Development Lab is such a nice direction to go in incorporating technology in the classroom, because it makes *learning+ more interactive," Sloan said. "The kids love it because they are active.
\end{abstract}

\section{KEYWORDS}

Teaching - Learning, 3D Environment, Augmented Reality , 3D Visualization

\section{INTRODUCTION}

The classroom lessons are engaging experiences with augmented reality (AR), a technology that overlays digital information on top of real-world surroundings as viewed through a smart phone or other handheld, GPS-enabled device." It's not just about throwing technology in these classrooms, it's about empowering the teachers to understand the technology," Jochim said. "Grasping the capability behind it gives teachers tools that are easy to use." "This ... is clearly going torevolutionize education,"

Augmented reality (AR) is the registration of projected computer-generated images over a user's view of the physical world. With this extra information presented to the user, the physical world can be enhanced or augmented beyond the user's normal experience. The addition of information that is spatially located relative to the user can help to improve their understanding of it. In 1965, Sutherland described his vision for the Ultimate Display [SUTH65], with the goal of developing systems that can generate artificial stimulus and give a human the impression that the experience is actually real. Sutherland designed and built the first optical head mounted display (HMD) that was used to project computer-generated imagery over the physical world. This was the first example of an augmented reality display[SUTH68]. Virtual reality (VR) was developed later using opaque display technology to immerse the user into a fully synthetic environment. One of the first integrated environments was by Fisher et al., combining tracking of the head for VR with the use of tracked gloves as an input device.Augmented reality and virtual reality share common features

DOI : $10.5121 /$ ijist.2016.6209 


\subsection{Hardware / Software requirements Specification}

The main hardware components for augmented reality are:

Processor or CPU : The computer analyzes the sensed visual and other data to synthesize and position augmentations

Display/Output : To display the output, the programmer can use any of these following type screens, devices like:

\section{Projection displays}
CAVE-type
IDesk /Iscreen
Head mounts
Fishbowl VR

- To do stereo, you must get a different image to each eye trivial for head mounts

shutter glasses, left \& right images temporally interleaved

polarized glasses or red/blue glass

need several loudspeakers, carefully phased

might need model of listener's head shape

Sensors : Sense users attention and emotions:

$\begin{array}{llll}\text { gesture } & \square & \text { posture } & \square \text { voice } \\ \text { breathing } & \square \text { pulse \& blood } & \square \text { electrical activity of } & \square \text { skin } \\ & \text { pressure } & \text { muscles } & \text { conductance }\end{array}$

\section{Input devices}

Techniques include the pinch glove, a wand with a button and a smart phone that signals its position and orientation from camera images.

\begin{tabular}{|l|l|l|}
\hline$\square$ joystick, trackball & $\begin{array}{l}\text { pressure-sensitive } \\
\text { stylus }\end{array}$ & Wand \\
\hline $\begin{array}{l}\square \\
\begin{array}{l}\text { a simple way of } \\
\text { grasping virtual objects }\end{array}\end{array}$ & Data glove & $\begin{array}{l}\text { tracker with buttons } \\
\text { attache }\end{array}$ \\
\hline
\end{tabular}

Artificial information about the environment and its objects can be overlaid on the real world. Augmented reality provides the students with: 


\title{
Dynamic content
}

\author{
Engagetechnology-driven \\ learnersLeverage \\ handheld technology
}

\section{Digitally archive of Instruction}

Unlike Virtual Reality (VR) that aims at replacing the perception of the world with an artificial one, Augmented Reality (AR) has the goal of enhancing a person's perception of the surrounding world. Being partly virtual and real, the new interface technology of AR which is able to display relevant information at the appropriate time and location, offers many potential applications; these include aiding in education, training, repair or maintenance, manufacturing, medicine, battlefield, games and entertainment.

\section{Review Of Literature}

An ICT-supported setting may offer interesting possibilities for the learning of mathematics because it can, and often does, provide students with several representations with which they can work (Parnafes \& diSessa, 2004). Further variation of representations may be offered by allowing for students to make use of real objects in the virtual setting, thereby providing opportunity for students to interact physically with the virtual objects and also providing tangible Feedback(Scarlatos, 2006).The present paper is part of an ongoing project regarding design of ICT-supported learning activities, which are developed in collaboration between researchers in mathematics education, researchers/developers in media technology and high school teachers. A central aspect in this work is to investigate the use of augmented reality $(A R)$, a technology that allows for mixing real-world images with computer generated images (Milgram \& Kishino, 1994).

Although Sutherland already in the 1960's (1965) developed the first AR interface, it is only recently that researchers have explored its potential uses for formal education (Zhou et al., 2008). Instead of the user wearing or carrying the display such as with head-mounted displays or handheld devices, Spatial Augmented Reality (SAR) makes use of digital projectors to display graphical information onto physical objects. The key difference in SAR is that the display is separated from the users of the system. Because the displays are not associated with each user, SAR scales naturally up to groups of users, thus allowing for collocated collaboration between users. SAR has several advantages over traditional head-mounted displays and handheld devices. The user is not required to carry equipment or wear the display over their eyes. This makes spatial AR a good candidate for collaborative work, as the users can see each other's faces. Augmentations cannot simply hang in the air as they do with handheld and HMD-based AR. The tangible nature of SAR,though, makes this an ideal technology to support design, as SAR supports both a graphical visualization and passive sensation for the end users. People are able to touch physical objects, and it is this process that provides the passive hectic sensation 


\section{Applications}

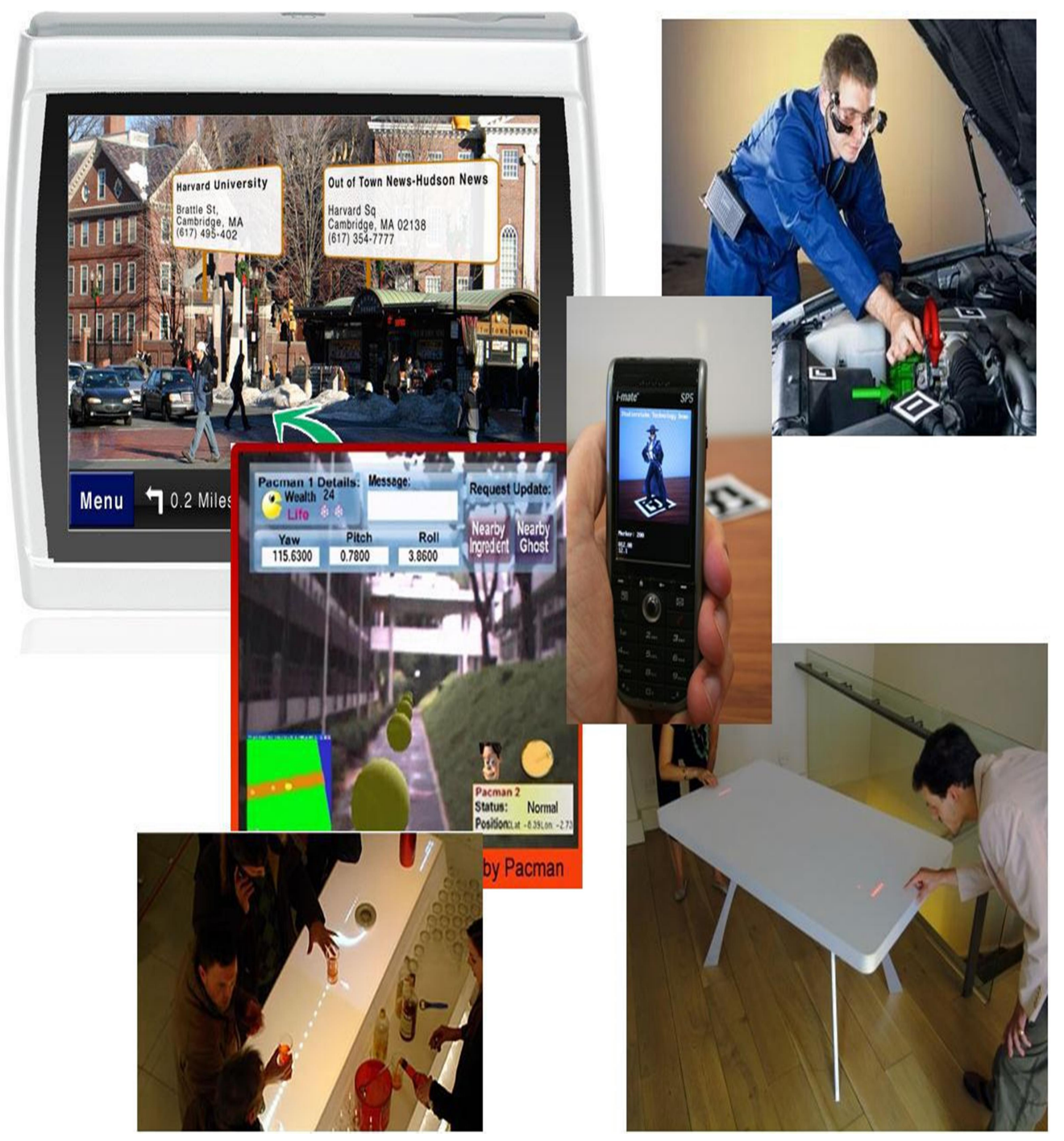

\section{The computing view}

Augmented Reaility Marker based experiment development is possible now, it has mainly two vision (view).

\subsection{Source view}

From the user's perspective, an interaction technique is a way to develop some 3D object in various software like 3D MAX and other softwre and make it image view and send some of the 
International Journal of Information Sciences and Techniques (IJIST) Vol.6, No.1/2, March 2016

images to uforia for creating image QR code for ready for Augmented Reiality. Uforia send some of the image with ready of augmented reality.

\subsection{User's view}

From the user interface User's view by smart phone camera it is compulsory to develop QR code detect apk file by which when smart phone camera we mount we can clearly see that 3D image by our smart phone. By learner's perspective if we set this Augmented reality and convert some theory topic to practical base and explain some laboratory base concept in theory class only by subject teacher.

\subsection{Development Framework}

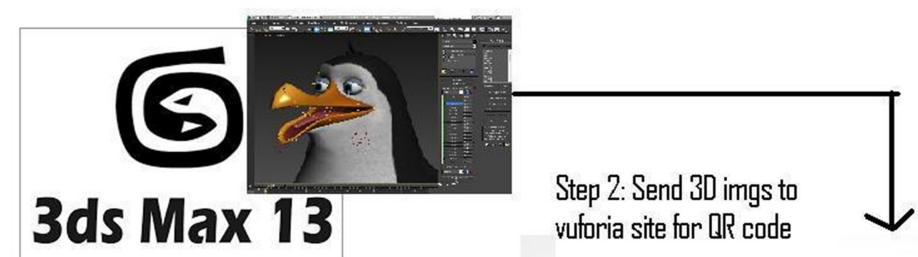

$$
\text { Step } 1 \text { : Develop 3D picture in sw (3D }
$$
max . maya ..... etc)
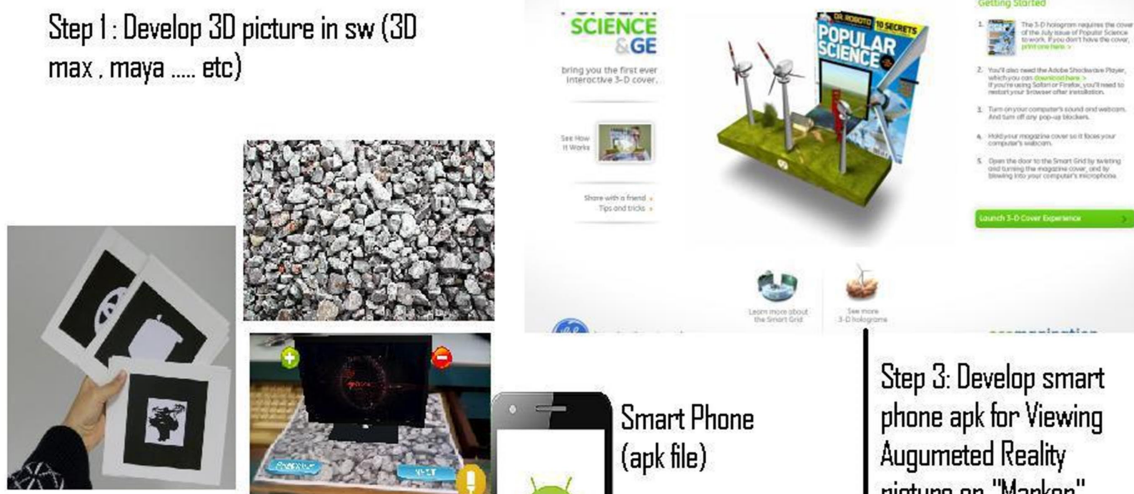
Step 4 : Focus Smart Phone camera on marker and you can see 3D images through "Marker" and smart phone apk

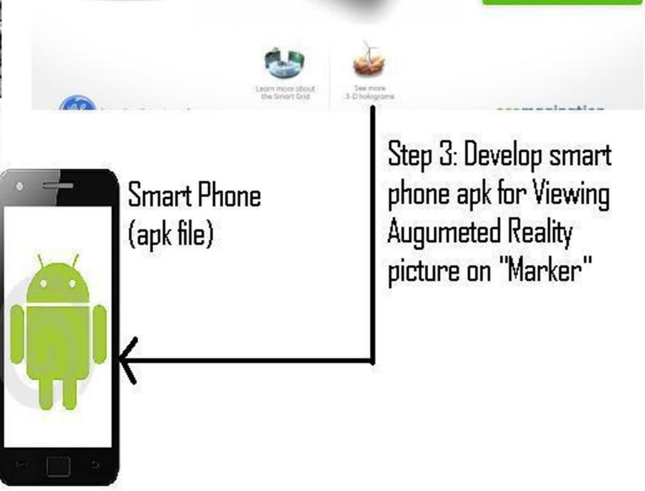

Process Architecture(Framework) for Developing 3D-"Marker" 


\subsection{Implementation of "3D Marker Based Augmented Reality"}

Some original implemented Example of "3D Marker Based Augmented Reality"
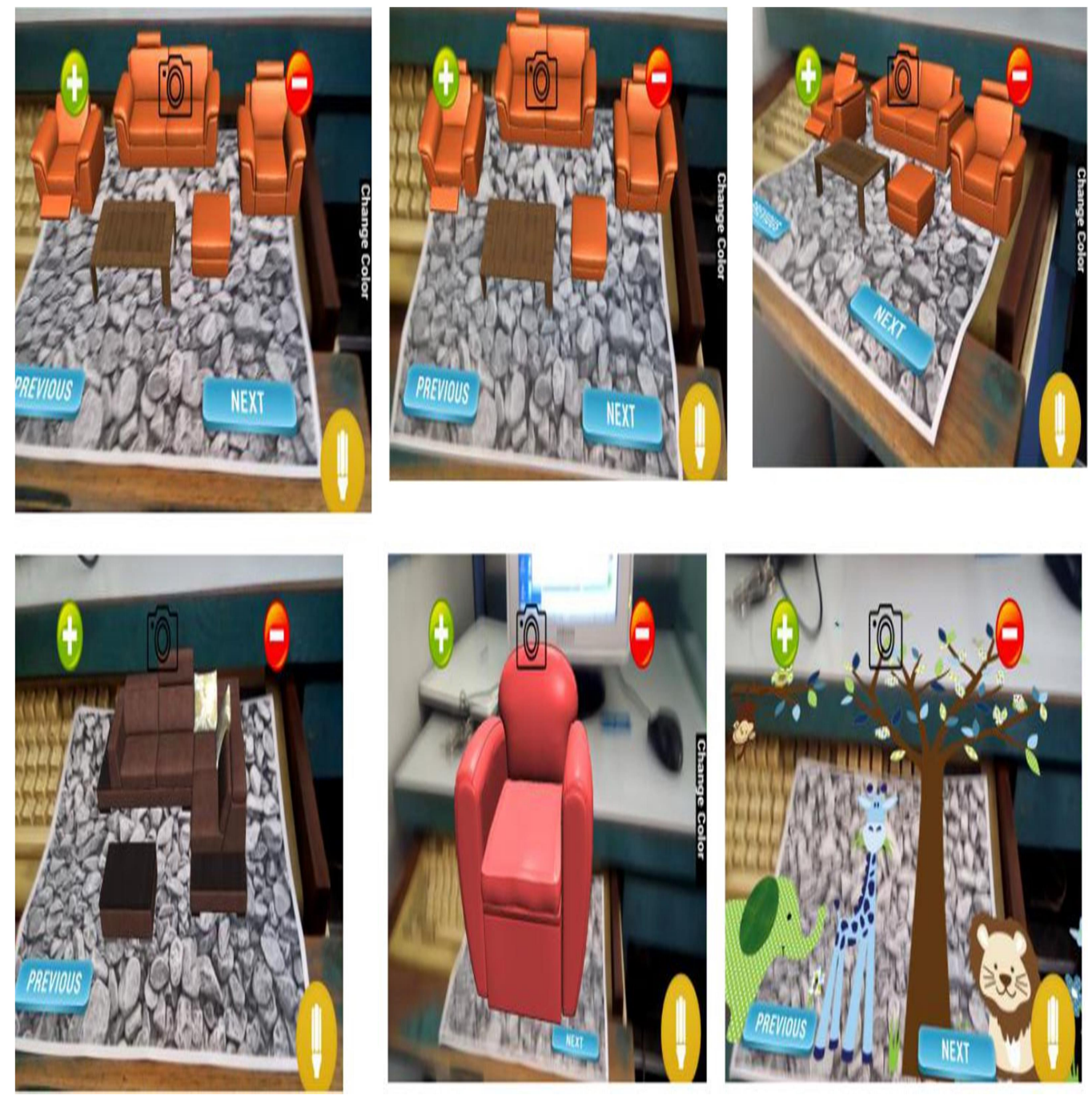

\section{Testing \& Results}

Null Hypothesis : H0 : No significance difference between evaluations scores before and fter utilizing Marker baased Augmented Reality (AR).

Alt. Hypothesis : H1 : Significance difference between evaluations scores before and after utilizing Marker based Augmented Reality (AR). 
International Journal of Information Sciences and Techniques (IJIST) Vol.6, No.1/2, March 2016

\begin{tabular}{|c|c|c|c|c|c|c|}
\hline $\mathrm{N}$ & before (x1) & $\left(\mathrm{x} 1^{\wedge} 2\right)$ & $\begin{array}{l}\text { after } \\
(\mathrm{x} 2)\end{array}$ & $\left(\mathrm{x} 2^{\wedge} 2\right)$ & diff & $\operatorname{diff}^{\wedge} 2$ \\
\hline 1 & 76 & 5776 & 86 & 7396 & -10 & 100 \\
\hline 2 & 73 & 5329 & 76 & 5776 & -3 & 9 \\
\hline 3 & 64 & 4096 & 84 & 7056 & -20 & 400 \\
\hline 4 & 56 & 3136 & 67 & 4489 & -11 & 121 \\
\hline 5 & 56 & 3136 & 60 & 3600 & -4 & 16 \\
\hline 6 & 71 & 5041 & 87 & 7569 & -16 & 256 \\
\hline 7 & 81 & 6561 & 89 & 7921 & -8 & 64 \\
\hline 8 & 54 & 2916 & 66 & 4356 & -12 & 144 \\
\hline 9 & 89 & 7921 & 90 & 8100 & -1 & 1 \\
\hline 10 & 60 & 3600 & 78 & 6084 & -18 & 324 \\
\hline 11 & 52 & 2704 & 69 & 4761 & -17 & 289 \\
\hline 12 & 44 & 1936 & 65 & 4225 & -21 & 441 \\
\hline 13 & 57 & 3249 & 77 & 5929 & -20 & 400 \\
\hline 14 & 74 & 5476 & 93 & 8649 & -19 & 361 \\
\hline 15 & 55 & 3025 & 59 & 3481 & -4 & 16 \\
\hline 16 & 85 & 7225 & 79 & 6241 & 6 & 36 \\
\hline
\end{tabular}

\begin{tabular}{|r|r|r|r|r|r|r|}
\hline 17 & 90 & 8100 & 87 & 7569 & 3 & 9 \\
\hline 18 & 76 & 5776 & 86 & 7396 & -10 & 100 \\
\hline 19 & 52 & 2704 & 78 & 6084 & -26 & 676 \\
\hline 20 & 44 & 1936 & 73 & 5329 & -29 & 841 \\
\hline 21 & 57 & 3249 & 86 & 7396 & -29 & 841 \\
\hline 22 & 63 & 3969 & 63 & 3969 & 0 & 0 \\
\hline 23 & 56 & 3136 & 60 & 3600 & -4 & 16 \\
\hline 24 & 58 & 3364 & 86 & 7396 & -28 & 784 \\
\hline 25 & 84 & 7056 & 90 & 8100 & -6 & 36 \\
\hline & 1627 & 110417 & 1934 & 152472 & -307 & 6281 \\
\hline $\begin{array}{l}\text { Averag } \\
\text { e }\end{array}$ & 65.08 & & 77.36 & & & \\
\hline St. Dev. & 13.464 & & 10.692 & & & \\
\hline
\end{tabular}

\begin{tabular}{|c|c|l|l|l|l|}
\hline Comp. & & & $\begin{array}{c}\text { calculated at } \\
\% 5\end{array}$ & & \\
$\mathrm{~T}$ & -3.50 & & \multicolumn{3}{|c|}{ T from table value from d.f. of 24 for $5 \%$ significance } \\
\hline Crit. $\mathrm{T}$ & 2.06 & & \multicolumn{3}{|c|}{} \\
\hline
\end{tabular}


International Journal of Information Sciences and Techniques (IJIST) Vol.6, No.1/2, March 2016

Critical $\mathrm{T}=2.06$ at $5 \%$ level of significance with d.o.f. (degrees of freedom) : 24 Computed $\mathrm{T}=-3.50$

Computed $\mathrm{T}$ falls in rejection region therefore $\mathrm{H} 0$ is rejected and hence $\mathrm{H} 1$ is accepted.

Impact : This justifies the higher performance of learners after utilizing Marker bsed Augmented Reaility (AR).

\section{CONCLUSION}

Augmented Reality is such a technology through which Augmented objects can be overlayed into the real world. This is a hot and trendy technology. In the educational field it can be used for demonstration of various practicals. Even theoretical concepts can be made very fascinating to learn. As per the survey conducted education done under Augmented reality showed very positive result as compared with the traditional educational system. In future Augmented reality will replace the traditional learning system. Augmented reality will be used E-Commerece, Digital Marketing, Educational Resources, Industrial, Military and Medical fields. The future of Augmented Reality is very admirable.

\section{REFERENCE}

[1] M. Bajura and U. Neumann "Dynamic registration correction in augmented-reality systems",Virtual Reality Annual International Symposium (VRAIS) \'95, pp.189-196 1995

[2] H. Koike and M. Kobayashi "Retrieving and manipulating digital information on EnhancedDesk", Proc. of APCHI I'98, 1998

[3] W. Press, S. Teukoisky, W. Vetterling and B. Flannery Numerical recipes in C, 1992 :Cambridge University Press

[4] J. Rekimoto and K. Nagao "The world through the computer: Computer augmented interaction with real world environments", Proceedings of UIST`'95, pp.29 -36 1995

[5] A. State , G. Hirota , D. T. Chen , W. F. Garrett and M. A. Livingston "Superior augmented reality registration by integrating landmark tracking and magnetic tracking", SIGGRAPH'96 Proceedings, 1996

[6] A. Takahashi , I. Ishii , H. Makino and M. Nakashizuka "A high accuracy realtime 3D measuring method of marker fo VR interface by monocular vision", 3D Image Conference \'96, pp.167 - 172 1996

[7] M. Uenohara and T. Kanade "Real-time vision based object registration for image overlay",Journal of the Computers in Biology and Medicine, pp.249 -260 1995

[8] P. Wellner "Interacting with paper on the DigitalDesk", Communication of the ACM, vol. 36, no. 7, pp.87 -96 1993 